\title{
Germination Eco-physiology and Emergence of Physalis peruviana Seedlings
}

\author{
Anderson Luis Nunes ${ }^{1}$, Serleni Sossmeier ${ }^{2}$, Ana Paula Gotz ${ }^{1}$ and Noryam Bervian Bispo ${ }^{1}$ \\ 1. IFRS, Instituto Federal de Educação Ciencia e Tecnologia do Rio Grande do Sul, Sertão 99170-000, RS, Brazil \\ 2. Postgraduate Program in Agronomy_PPGAgro, Universidade de Passo Fundo, Passo Fundo 99.052-900, RS, Brazil
}

\begin{abstract}
The genus Physalis belongs to the family Solanaceae, Physalis peruviana L. being the most cultivated species. As a newly explored crop in Brazil, little is known about its germination ecology and emergence under local conditions. The aim of the present study was to determine the effect of temperature, photoperiod, planting depth and seed dormancy on the establishment of Physalis seedlings. Tests were conducted on two Physalis biotypes from Sertão (Rio Grande do Sul state-RS) and Capelinha (Minas Gerais state). Seeds incubated at $27{ }^{\circ} \mathrm{C}$ and $32{ }^{\circ} \mathrm{C}$ exhibited high germination percentages of $98 \%$ and $96 \%$, respectively. Germination declined when seeds were incubated at $12,17,22$ and $37^{\circ} \mathrm{C}$. Photoperiods longer than $8 \mathrm{~h}$ are sufficient for seed germination, while the absence of light significantly reduces the germination percentage. Seeds should be planted at a depth of 1-2 cm to ensure better seedling emergence. After 18 months of field work, $81 \%$ of seeds had germinated and/or been predated prior to assessment, indicating low seed dormancy. As such, ideal conditions for Physalis seedling establishment are planting depth between $1 \mathrm{~cm}$ and 2 $\mathrm{cm}$, temperatures ranging from $27^{\circ} \mathrm{C}$ to $32^{\circ} \mathrm{C}$ and a photoperiod longer than $8 \mathrm{~h}$, with a postharvest seed shelf life of $12 \mathrm{months}$.
\end{abstract}

Key words: Temperature, photoperiod, planting depth, dormancy.

\section{Introduction}

The cultivation of small fruits has gained ground among family farmers due to low cost of crop implementation and good economic returns. In Brazil, fruit farming contributes significantly to economic growth with 2.5 ha producing approximately 40 million metric tons of fruit per year [1]. Among small fruits, Physalis increasingly stands out, largely due to its nutritional and economic value. Physalis belongs to the family Solanaceae, Physalis peruviana L. being the most widely known species in the genus [1]. The species is native to Andean countries [2], primarily Peru, Columbia and Ecuador and easily adapts to different climate conditions and soil types. The plant is perennial and reaches height between $1.5 \mathrm{~m}$ and 2.0 $\mathrm{m}$ [3]. The main stem is herbaceous, exhibiting 8-12 nodes, each node producing a vegetative and reproductive bud [4]. The leaves are simple and

Corresponding author: Anderson Luis Nunes, Ph.D., research field: plant breeding. alternate. Flowers are hermaphrodite with five yellow petals. The sepals are green and form the chalice that covers the fruit throughout its development [5]. The fruit is a berry, weighing from $4 \mathrm{~g}$ to $10 \mathrm{~g}$ and containing 100-300 seeds. It also has high nutritional value, containing vitamins $\mathrm{A}$ and $\mathrm{C}$, as well as flavonoids and carotenoids [6]. Physalis leaf extract can be used as an antifungal, antioxidant, antitumor and anti-inflammatory agent due to the bioactive components it contains [7-9].

$P$. peruviana L. is well known in the south-central region of the country, where it is grown. However, it remains unknown in other areas and is often confused with $P$. angulata L., which occurs naturally in fields and gardens [10]. Both species are easily propagated through seeds and are therefore considered weeds in many crops [11]. In cotton crops, for example, the genus Physalis is viewed as invasive and difficult to control [12]. Weed Physalis species were tested under water and salinity stresses in semi-arid regions and is expected that $P$. philadelphica develops best under 
optimal water supply and high salinity, while $P$. angulata can better develop in water limited environments [13].

Research has been conducted on the general aspects of the Physalis cultivation, such as fertilization, training and ideal ripeness levels for harvest. However, the optimum temperature and photoperiod required for Physalis seed germination has yet to be established. As such, the present study aimed to determine the ideal temperature and photoperiod for the germination of Physalis seeds, in addition to assessing seed dormancy and seedling emergence ability.

\section{Materials and Methods}

The experiments were conducted in Agriculture Sector I and the Plant Health Protection Laboratory of the Federal Institute of Science and Technology Education of Rio Grande do Sul state (IFRS) - Sertão campus. Climate in the region is classified as $\mathrm{Cfa}$ according to Köppen's classification system and the soil as Distroferric Red Nitisol [14].

\subsection{Seed Collection}

The experiments were conducted with two biotypes of $P$. peruviana $\mathrm{L}$. The seeds of biotype 1 were from the municipality of Sertão (RS) and those of biotype 2 from Capelinha (MG). The seeds were obtained in 2013 and released in the field during the 2013/2014 growing season. All the seeds used in this study were extracted from ripe fruit with yellow-green and straw yellow chalices [1]. Immediately after extraction, the seeds were washed and dried in the shade. Next, they were placed in paper bags and stored in a dry location away from the light and at ambient temperature until use.

\subsection{Temperature and Light}

Germination tests were performed in NT708 TR incubators (Novatécnica Laboratory Equipment) in order to determine the ideal temperature and photoperiod for Physalis seed germination. A completely randomized $2 \times 6$ factorial design was employed (two biotypes and six temperatures or six photoperiods), each consisting of four repetitions and 50 seeds. For the purpose of disinfestation, seeds were immersed for $1 \mathrm{~h}$ in commercial sodium hypochlorite solution (bleach) containing 2.5\% active chlorine and then rinsed using distilled water. Next, they were distributed on germitest paper and incubated at 12, 17, 22, 27, 32 and $37^{\circ} \mathrm{C}$, with a $12 / 12$ photoperiod. Seeds, which were considered germinated when they exhibited root protrusion, were counted up to $30 \mathrm{~d}$ after incubation. After the ideal temperature was established, tests were conducted to determine the optimum photoperiod, characterized by light/dark periods of $0 / 24,24 / 0,8 / 16,10 / 14,14 / 10$ and 12/12 $\mathrm{h}$. The same procedure used to ascertain the effects of temperature was applied to count the germinated seeds.

\subsection{Planting Depth}

The experiment was conducted in a greenhouse using a completely randomized $2 \times 7$ factorial design (two biotypes and seven depths), consisting of four repetitions and 100 seeds. Seven planting depths were assessed: 0 (planted on the surface without covering the seeds), 1, 2, 4, 6, 8 and $12 \mathrm{~cm}$. The seeds were distributed in $0.0003 \mathrm{~m}^{3}$ pots and covered with a mixture of soil and peat (commercial brand Carolina Padrão ${ }^{\circledR)}$ at a proportion of $1: 1$. The emerged seedlings were counted $30 \mathrm{~d}$ after planting.

\subsection{Seed Dormancy}

The experiment used a completely randomized $2 \times$ 4 factorial design (two biotypes and four periods), with four repetitions of 100 seeds. Seeds covered in Carolina Padrão ${ }^{\circledR}$ peat substrate were placed in $10 \mathrm{~cm}$ $\times 25 \mathrm{~cm}$ organza bags and buried in soil $7 \mathrm{~cm}$ deep on May 6, 2014; $50 \mathrm{~d}$ after seeds were extracted from fruits. In order to determine seed viability, the bags were dug up 1, 6, 12 and 18 months after the test began. The seeds were washed and disinfected, placed 
on germitest paper and incubated at $27{ }^{\circ} \mathrm{C}$ using a 12/12 (light/dark) photoperiod. Germinated seeds were counted up to $15 \mathrm{~d}$ after incubation. Seeds that germinated during incubation, but not in the burial period, were considered dormant. Seeds that did not germinate after burial or incubation were submitted to tetrazolium chloride test.

\subsection{Statistical Analysis}

The data obtained from all experiments were submitted to the Shapiro-Wilk test of normality, indicating the need for data transformation. Arcsine transformation was applied when necessary. Data were submitted to analysis of variance using the F-test ( $1 \%$ to $5 \%$ probability). Means were compared by Tukey's test at 5\% probability. To determine the effect of temperature, photoperiod and planting depth, regression analysis was applied according to significance determined by the F-test, at $1 \%$ or $5 \%$ probability. Exponential regression was used for the photoperiod, quadratic polynomial regression for temperature and logistic sigmoid regression for planting depth. Regressions and graphs were compiled with Sigma Plot 12.5 software.

\section{Results and Discussion}

\subsection{Effect of Temperature and Light}

The germination response to temperature exhibited a quadratic model for both biotypes (Fig. 1a). The highest germination percentages (98\% and 96\%) occurred at temperatures of $27{ }^{\circ} \mathrm{C}$ and $32{ }^{\circ} \mathrm{C}$, respectively (Fig. 1a). At these temperatures, a higher water imbibition speed could have occurred, which activated the metabolic reactions inside the seed, allowing the emission of the radicle. Water imbibition is one of the key factors in triggering the germination process and the development of normal seedlings. Germination declined at $17^{\circ} \mathrm{C}$ and $37^{\circ} \mathrm{C}$, with $17 \%$ and $36 \%$ of seeds germinated, respectively. Germination onset for seeds incubated at $17{ }^{\circ} \mathrm{C}$ was $20 \mathrm{~d}$. However, at higher temperatures, such as $27^{\circ} \mathrm{C}$, all viable seeds had germinated after $15 \mathrm{~d}$ of incubation (data not shown). P. angulata L. seeds exposed to temperatures of $15{ }^{\circ} \mathrm{C}$ only began germinating on day 17 of incubation, with the highest germination rate observed at $27{ }^{\circ} \mathrm{C}$ [15]. Additionally, the highest germination rates for $P$. philadelphica Lam. are observed at temperatures between $25^{\circ} \mathrm{C}$ and $30{ }^{\circ} \mathrm{C}$ [16]. Comparison of the response of biotype 1 seeds collected in 2013 and 2014 showed similar behavior, except for a temperature of $17^{\circ} \mathrm{C}$ (Fig. 1b). At this temperature, seeds stored for one year exhibited higher germination in relation to those collected in 2014. As such, there is no reason to favor seeds collected in one year over another, provided they are properly stored. These results differ from the data found with $P$. angulata, where the seeds lost $50 \%$ viability after $45 \mathrm{~d}$ of storage [17]. According to the authors, the seeds of $P$. angulata are orthodox and can be conserved for more than $45 \mathrm{~d}$ if the water content in the seeds is reduced and if the temperature and the relative humidity during storage are adequate [17].

With respect to photoperiod, germination showed exponential behavior (Figs. 2a-2d). Physalis seeds exhibited low germination percentages in the absence of light. $P$. peruviana L. seeds kept in the dark did not germinate [18]. An average germination percentage of $97 \%$ was recorded under an 8 -h light regime, indicating that the species is positively photoblastic. The biotype 1 seeds collected in 2013 showed greater standard deviation in repetitions compared to those collected in 2014 (Figs. 2c and 2d). In the dark, seeds collected in 2013 and 2014 demonstrated average germination of $58 \%$ and $40 \%$, respectively. Germination testing as a function of temperature for seeds collected in 2013 and 2014 showed no differences for the ideal temperatures of $27{ }^{\circ} \mathrm{C}$ and $32{ }^{\circ} \mathrm{C}$. However, assessment of the photoperiod at $27^{\circ} \mathrm{C}$ indicated irregular behavior for seeds collected in 2013. P. ixocarpa Brot. seeds stored for $1-5$ years showed a $6.9 \%$ annual reduction in emergence [19]. 

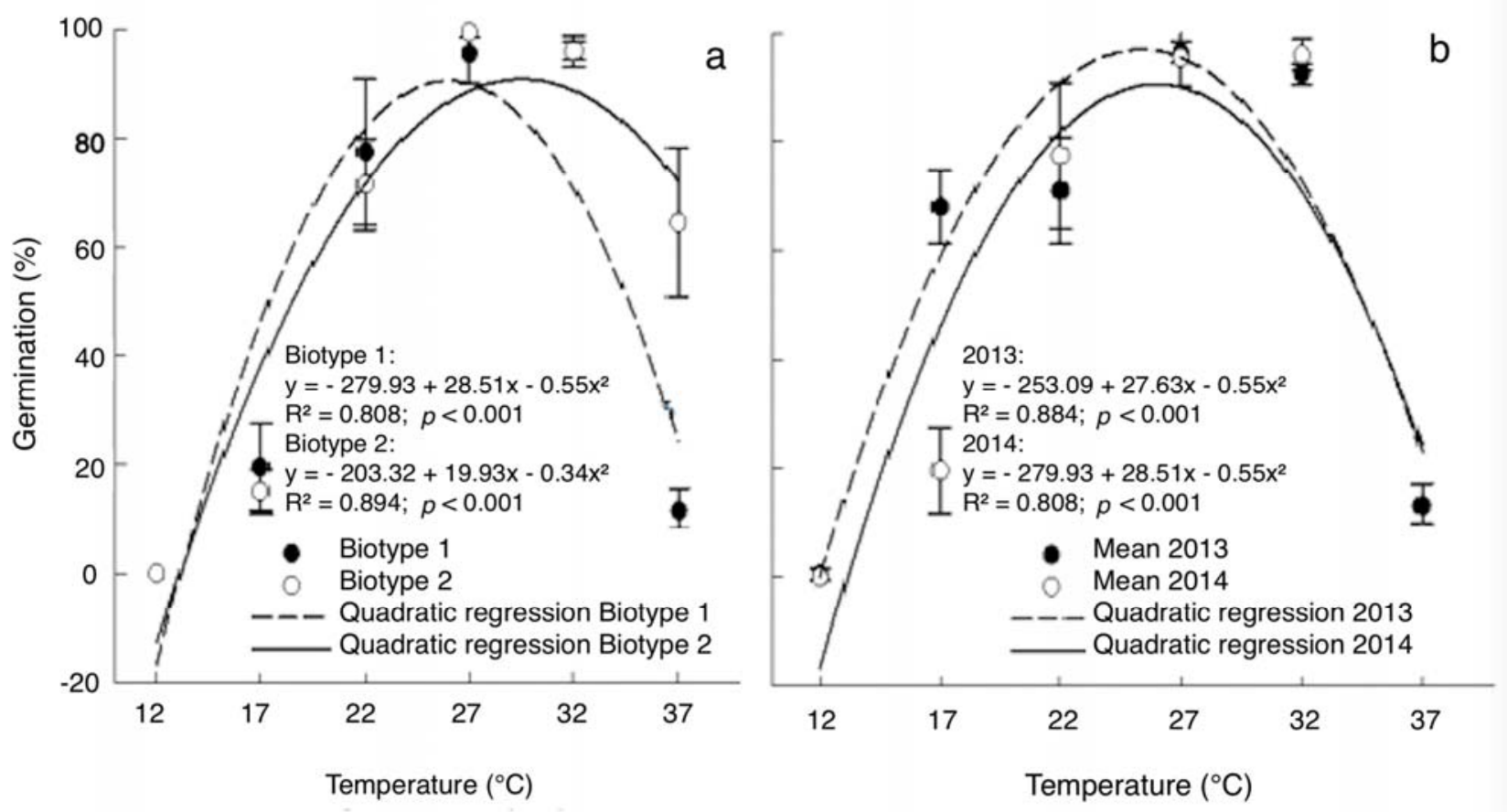

Fig. 1 Effect of temperature on Physalis seed germination.

(a) biotype 1 (black points) and biotype 2 (white points); (b) biotype 1 seeds collected in 2013 (black points) and 2014 (white points).

\subsection{Effect of Planting Depth}

Emergence of Physalis seedlings as a function of planting depth displayed logistical behavior for both biotypes (Fig. 3). Depths of $1 \mathrm{~cm}$ and $2 \mathrm{~cm}$ showed emergence of $92 \%$ and $93 \%$, respectively, for biotype 1 , and $92 \%$ and $83 \%$, respectively, for biotype 2. These results corroborate those observed in the light regime experiment, presented in Fig. 2 as a function of the light required for germination to occur. A planting depth of $1.5 \mathrm{~cm}$ is the most recommended for tomato crops (Lycopersicon esculentum Mill.), a cultivated species belonging to the same family as Physalis [20]. However, greater depth resulted in lower seedling emergence, with the highest emergence (10\% and $15 \%)$ recorded at $12 \mathrm{~cm}$ for biotypes 1 and 2, respectively. This reduction in emergence is related to the greater physical resistance imposed by thicker soil layers. This effect negatively affects the rapid and uniform initial establishment of the seedling stand and may also affect the competitive ability and productive potential of the species. Physalis has low seed reserves, which results in lower production and availability of energy to break down the soil layers. The seeds distributed on the surface $(0 \mathrm{~cm})$ also showed a decline in emergence percentage. This was observed in the field, where the Physalis seeds planted on the surface of the soil were affected by insects, primarily ants (data not shown). Solanum viarum seeds placed on the surface exhibited lower germination and leaning of seedlings since they were less anchored in the soil [21].

\subsection{Effect of Seed Dormancy}

Seed dormancy ensures the survival of most weeds. These seeds germinate at different times of the year in order to perpetuate the species. The dormancy test indicated low dormancy for Physalis seeds when compared to wild plants. ANOVA found no difference between biotypes in the dormancy test; as such, the data presented in Fig. 4 represent the means of both biotypes. There was no difference between seeds buried 

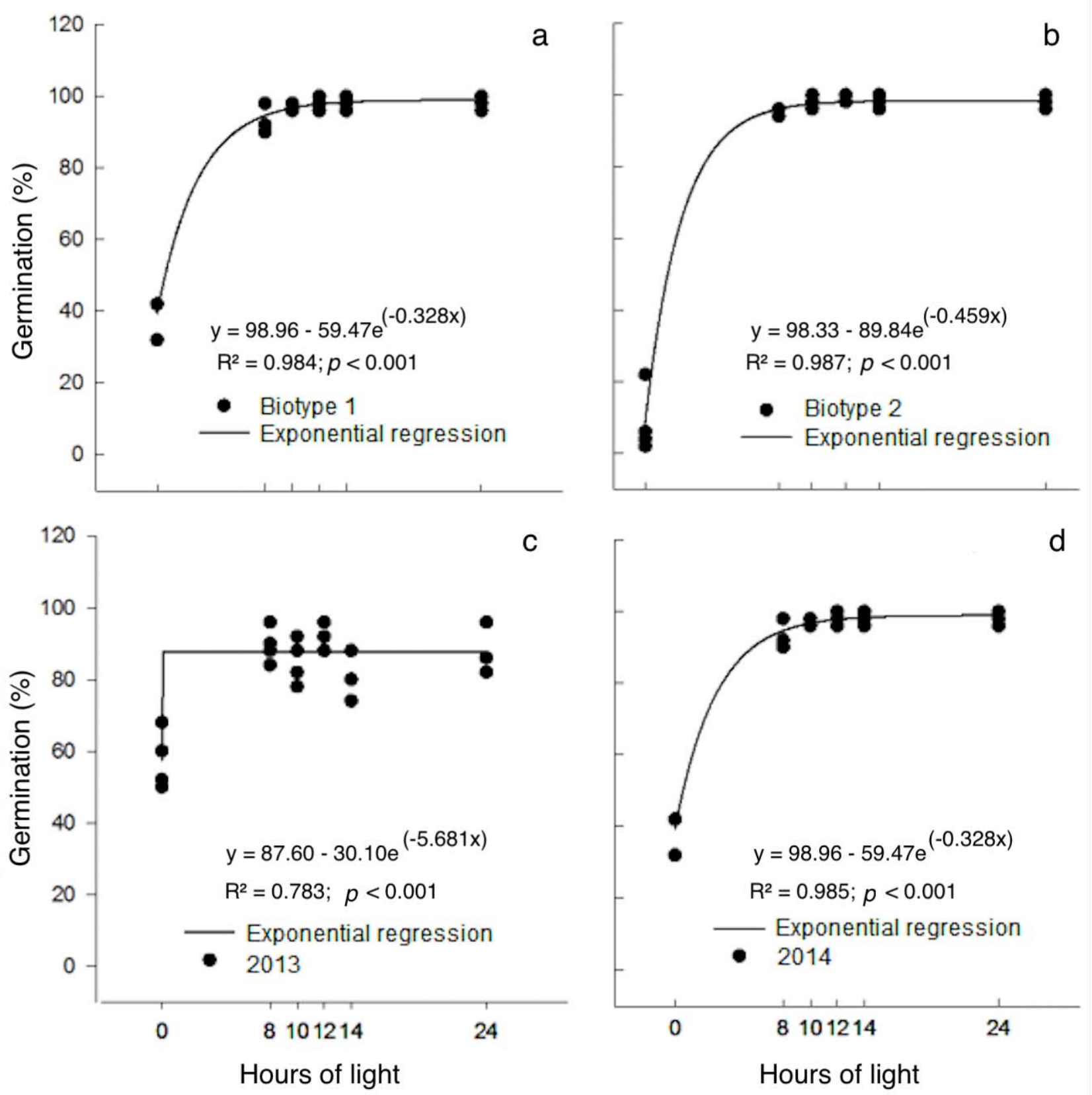

Fig. 2 Effect of light regimes on Physalis germination.

(a) biotype 1, (b) biotype 2, (c) and (d) show the results of biotype 1 for seeds collected in 2013 and 2014, respectively.

for one month and six months; however, a difference was observed between these seeds and those buried for 12 months and 18 months in terms of the number of predated, germinated and dormant seeds. At 12 months and 18 months, $78 \%$ and $81 \%$ of seeds, respectively, had germinated and/or been predated prior to assessment, indicating low dormancy. $P$. philadelphica Lam. seeds exhibited dormancy, since an average germination percentage of $92 \%$ was recorded at temperatures of $20^{\circ} \mathrm{C}$ to $35^{\circ} \mathrm{C}$ [16]. The dormancy of $S$. americanum is interrupted by fluctuating temperatures in the environment and rapid seed imbibition [22]. Dormancy interrupted by varying temperatures may explain the high rate of germinated Physalis seeds in the field during the 12-month burial period. Thus, seeds collected over a 


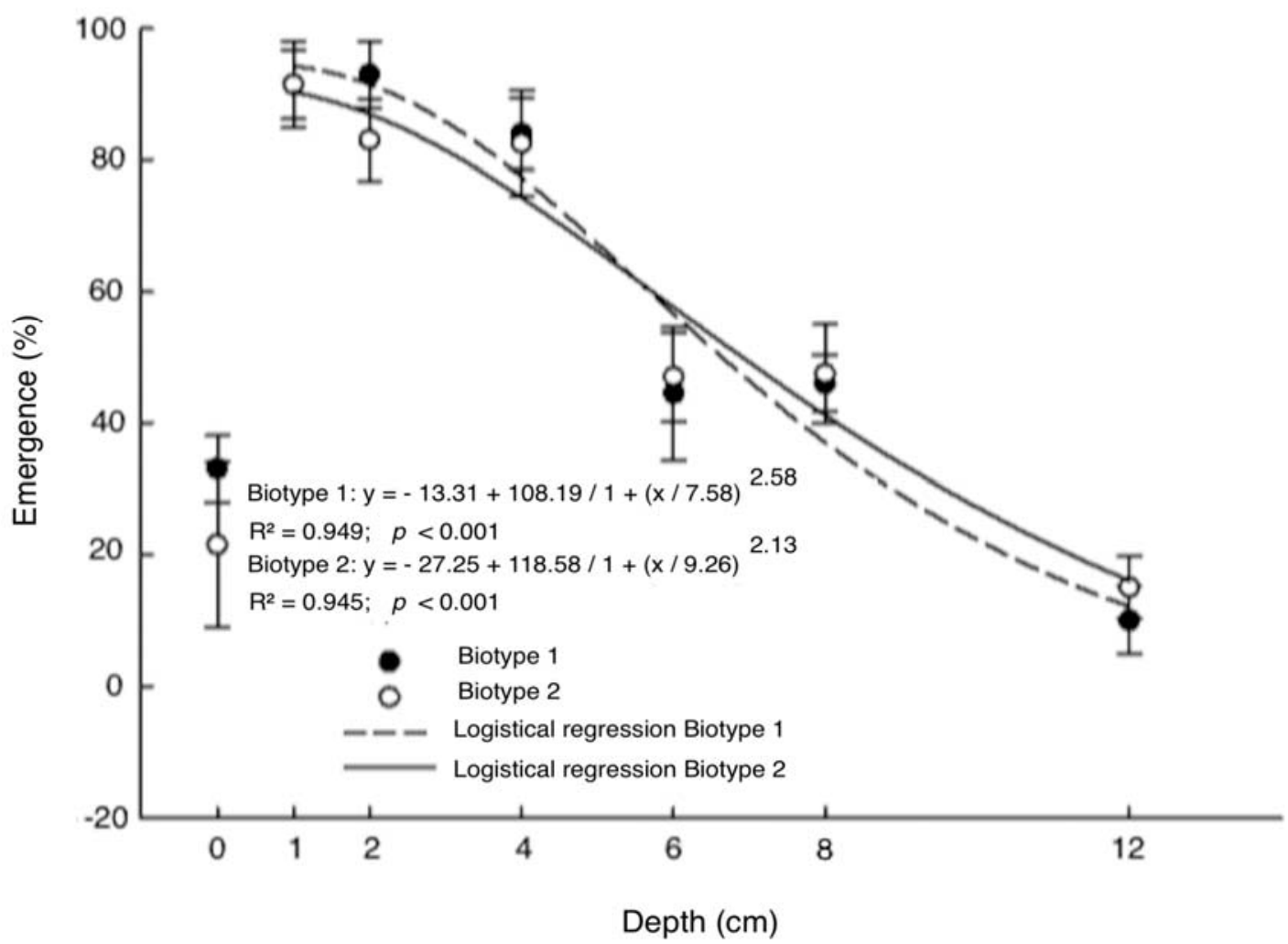

Fig. 3 Effect of planting depth on Physalis seedling emergence.

Black and white points are relative to biotypes 1 and 2, respectively; zero depth $(0 \mathrm{~cm})$ was not included in the regression and is only depicted in the graph.

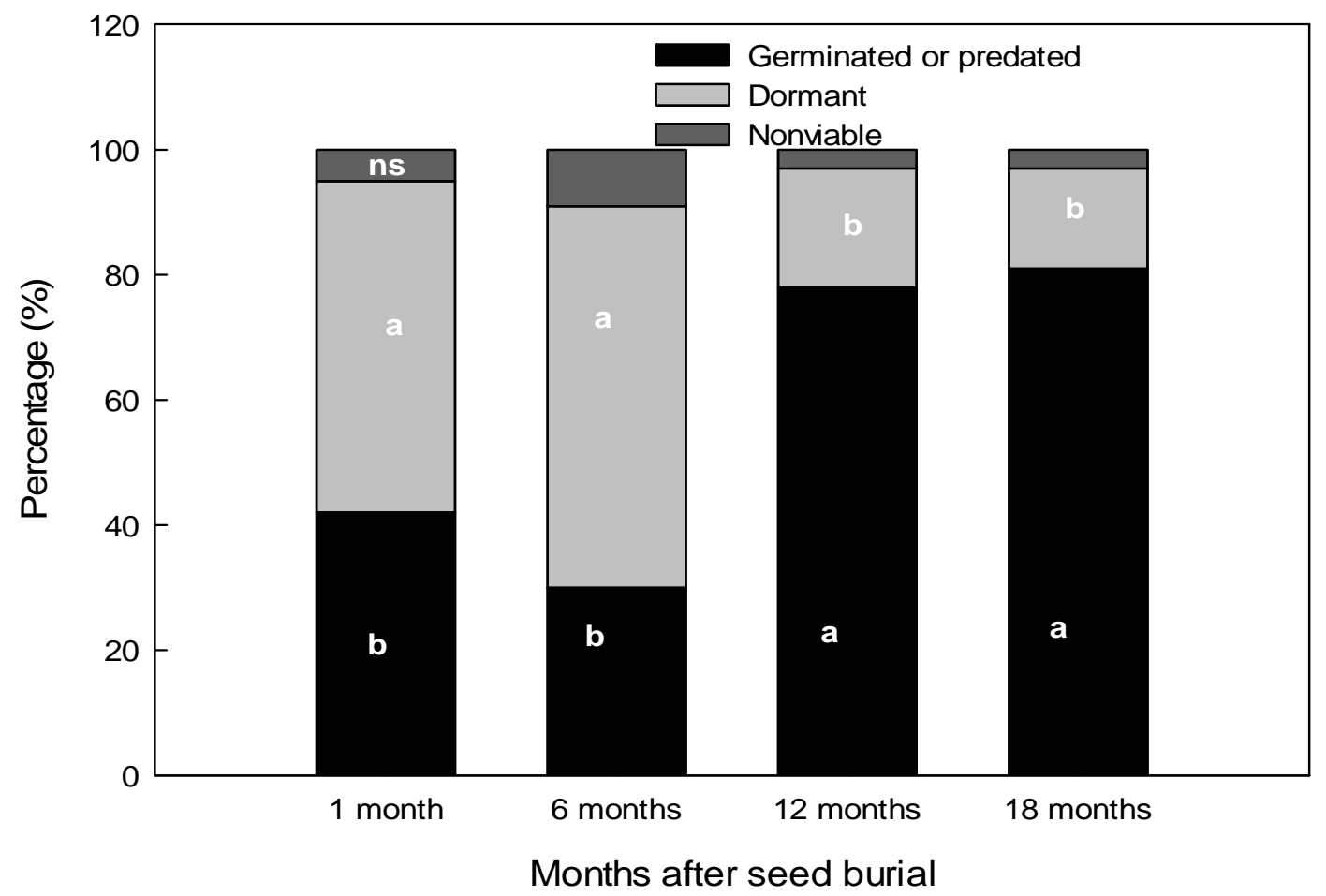

Fig. 4 Physalis seed dormancy evaluation following removal from the soil after 1, 6 and 12 months.

Means followed by the same letter indicate no significant difference (Tukey's test, $p<0.05$ ) between burial periods under the same conditions (germinated or predated, dormant or nonviable). 
12-month period can be used to establish Physalis seedlings.

The cultivation of Physalis is a possibility of income for small farms. The establishment of uniform and vigorous seedlings provides a more efficient cultivation of this species. However, it is necessary to study which species of Physalis has the highest productivity in the climatic conditions of Southern Brazil and studies to discovery selective herbicides to this crop.

\section{Conclusions}

As such, ideal conditions for Physalis seedling establishment are:

(1) Use a postharvest seed shelf life of 12 months;

(2) Planting depth between $1 \mathrm{~cm}$ and $2 \mathrm{~cm}$;

(3) Air temperatures ranging from $27^{\circ} \mathrm{C}$ to $32^{\circ} \mathrm{C}$;

(4) A photoperiod longer than $8 \mathrm{~h}$.

\section{Acknowledgments}

The authors would like to thank the Instituto Federal de Educação Ciência e Tecnologia do Rio Grande do Sul (IFRS) for the research support and grants awarded.

\section{References}

[1] Lima, C. S. M. 2009. "Phenology, Mentoring Systems and Production of Physalis peruviana in the Pelotas Region.” MSc. thesis, Federal University of Pelotas. (in Portuguese)

[2] Wilf, P., Carvalho, M. R., Gandolfo, M. A., and Cúneo, N. R. 2017. "Eocene Lantern Fruits from Gondwanan Patagonia and the Early Origins of Solanaceae." Science 355: 71-4.

[3] Fischer, G. 2000. "Production, Post-Harvest and Export of the Uchuva (Physalis peruviana L.)." In Growth and Development, edited by Flórez, V. J., Fischer, G., and Sora, A. D. Bogotá: Unibiblos, 9-26. (in Spanish)

[4] Lagos, T. C. 2006. "Reproductive Biology, Cytogenetics, Genetic Diversity and Heterosis in Uvilla or Uchuva Parental Physalis peruviana L." Ph.D. thesis, National University of Colombia, Palmira. (in Spanish)

[5] Ávila, J., Moreno, P., Fischer, G., and Miranda, D. 2006. "Influence of Fruit Maturity and Calyx Drying on Cape
Gooseberry (Physalis peruviana L.), Stored at $18{ }^{\circ} \mathrm{C} . "$ Acta Agronómica 55: 29-37. (in Spanish)

[6] Etzbach, L., Pfeiffer, A., Weber, F., and Schieber, A. 2018. "Characterization of Carotenoid Profiles in Goldenberry (Physalis peruviana L.) Fruits at Various Ripening Stages and in Different Plant Tissues by HPLC-DAD-APCI-MS ${ }^{n}$." Food Chemistry 245: 508-17.

[7] Muniz, J., Kretzschmar, A. A., Rufato, L., Pelizza, T. R., Rufato, A. R., and Macedo, T. A. 2014. "General Aspects of Physalis Cultivation.” Rural Science 44: 964-70. (in Portuguese)

[8] Mukungu, N., Abuga, K., Okalebo, F., Ingwela, R., and Mwangi, J. 2016. "Medicinal Plants Used for Management of Malaria among the Luhya Community of Kakamega East Sub-county, Kenya." Journal of Ethnopharmacology 194: 98-107.

[9] Wang, Y., Wang, S. L., Zhang, J. Y., Song, X. N., Zhang, Z. Y., Li, J. F., and Li, S. 2018. "Anti-ulcer and Anti-helicobacter Pylori Potentials of the Ethyl Acetate Fraction of Physalis alkekengi L. var. franchetii (Solanaceae) in Rodent." Journal of Ethnopharmacology 211: 197-206.

[10] Muniz, J. 2011. "Conduction Systems and Spacing for the Cultivation of Physalis (Physalis peruviana L.) on the Santa Catarina Plateau." MSc. thesis, State University of Santa Catarina, Lages. (in Portuguese)

[11] Souza, C. L. M. D., Souza, M. O., Oliveira, M. F., Oliveira, L. M., and Pelacani, C. R. 2010. "Seed Morphology and Post-Seminal Development of Physalis angulata L." Acta Botanica Brasilica 24: 1082-5. (in Portuguese)

[12] Inoue, M. H., Oliveira, J. R. S., Ben, R., Dallacort, R., and Sztoltz, C. L. 2013. "Selectivity of Herbicides Applied in Pre-emergence in Cotton Crop." Journal of Agronomic Science 44: 123-32. (in Portuguese)

[13] Ozaslan, C., Farooq, S., Onen, H., Bukun, B., Ozcan, S., and Gunal, H. 2016. "Invasion Potential of Two Tropical Physalis Species in Arid and Semi-arid Climates: Effect of Water-Salinity Stress and Soil Types on Growth and Fecundity." PLoS ONE 11 (10): 23.

[14] Embrapa. 2006. Brazilian System of Soil Classification. 2nd ed. Rio de Janeiro: Embrapa Soil, 306. (in Portuguese)

[15] Piva, A. L. 2013. "Seed Imbibition, Germination Temperature and Asexual Propagation of Physalis (Physalis spp.)." MSc. thesis, Western State University of Paraná, Marechal Cândido Rondon. (in Portuguese)

[16] Calzada, L. S. G., Shibata, J. K., Mortera, E. U., Esteva, A. G., and Jiménez, P. Y. 2014. "Cardinal Temperatures and Germination Velocity in Shell Tomato Cultivars." Journal of Mexican Agricultural Sciences 8: 1451-8. (in 
Spanish)

[17] Carvalho, T. C., D’Angelo, J. W. O., Scariot, G. N., Saes Júnior, L. A., and Cuquel, F. L. 2014. "Seed Germination of Physalis angulata L.: Stage of Maturity of the Chalice and Form of Storage." Tropical Agricultural Research 44 (4): 357-62. (in Portuguese)

[18] Chaves, A. D. C., Schuch, M. W., and Erig, A. C. 2005. "Establishment and in Vitro Multiplication of Physalis peruviana L." Science and Agrotechnology 29: 1281-7. (in Portuguese)

[19] Pérez-Camacho, I., Ayala-Garay, O. J., González-Hernandez, V. A., Carrillo-Salazar, J. A., Pena-Lomeli, A., and de los Santos, G. G. 2008. "Morphological and Physiological Indicators of the
Deterioration of Seeds of Shell Tomato.” Agro-science 42 891-901. (in Spanish)

[20] Tillmann, M. A. A., Piana, Z., Cavariani, C., and Minami, K. 1994. "Effect of Seeding Depth on Emergence of Tomato Seedlings (Lycopersicon esculentum Mill.)." Scientia Agricola 51: 260-3. (in Portuguese)

[21] Souza, M. C., Parreira, M. C., Amaral, C. L., and Alves, P. L. C. A. 2011. "Effect of the Season on the Emergence of Sida rhombifolia and Solanum viarum at Different Seeding Depths." Journal Ceres 58 (6): 749-54. (in Portuguese)

[22] Ladeira, A. M. 1997. "Numbness in Seeds of Maria-Pretinha." Brazilian Agricultural Research 32: 1317-23. (in Portuguese) 